\title{
A MEDIAÇÃo DIALÓGICA COMO INSTRUMENTO PARA PROMOVER A SAÚDE E COESÃO SOCIAIS: RESULTADOS E DIREÇÕES
}

\author{
Gian Piero Turchi \& Michele Romanelli
}

\begin{abstract}
Resumo
Um dos principais desafios na Europa é focar a atenção nas políticas públicas capazes de promover e manter a coesão social. Podemos ver como a interação entre diferentes sistemas culturais pode erradicar as diferenças. Uma vez que essas diferenças são assumidas como a caracterização e a identificação dos elementos de grupos sociais específicos, elas também podem causar conflitos na comunidade. Este artigo visa descrever os elementos que permitem a implementação da mediação nas políticas sociais. Será proposto um modelo operacional, tanto para usar em situações de emergência, como de antecipação de conflitos, em todos os níveis nos quais o conflito possa, por si, ser gerado ou desenvolvido: este modelo será denominado "Mediação dialógica" (Turchi \& Gherardini, 2014). Este modelo trabalha com as partes interessadas não só de forma direta, mas também através de todas as "vozes" que possam estar envolvidas nas repercussões que o conflito possa gerar (e, como consequência, com toda a comunidade). É aqui que a mediação pode ser oferecida como um instrumento de política pública para a gestão da interação dialógica entre a "comunidade imigrante" e a "comunidade de acolhimento", antecipando os conflitos e apoiando uma interação como "comunidade única".
\end{abstract}

\section{DiAlogiCAl MEDIATION AS AN INSTRUMENT TO PROMOTE HEALTH AND SOCIAL COHESION: RESULTS AND DIRECTIONS}

\begin{abstract}
One of the main challenges in Europe is to focus attention on public policies capable of promoting and maintaining social cohesion. We can see how the interaction between different cultural systems can radicalize the differences. Since those differences are assumed to characterize and identify elements of the specific social groups, they can cause conflicts in the community. This paper aims to describe the elements that allow the implementation of mediation in public policies. An operating model for both emergency use and in anticipation of conflict will be proposed for all the levels at which conflict itself may be generated or has developed: this model will be called "Dialogical Mediation" (Turchi \& Gherardini, 2014). This model operates on the interested parties not only in a direct way, but also through all the "voices" that may be involved in repercussions that the conflict may generate (the whole community as a consequence). This is when mediation can be offered as an instrument of public policy, for the management of dialogical interaction between the "migrant community" and the "hosting community", anticipating conflicts and sustaining interactions as a "single community".
\end{abstract}

KeYwORDS

Community; dialogical interaction; dialogical mediation; health; social cohesion 


\section{INTRODUÇÃO}

Na seguinte contribuição procura-se descrever os elementos que permitem utilizar a mediação como um instrumento disponível, não apenas para o sistema legal, mas também para as políticas públicas. Esta contribuição foca-se particularmente na gestão dos fluxos migratórios.

Após a descrição dos cenários resultantes dos fluxos migratórios, será analisado um estudo sobre a regulamentação a nível europeu para sublinhar uma série de aspetos críticos (de natureza operacional) atribuídos à mediação. Esta transição argumentativa irá permitir alcançar a proposta para uma teoria geral da mediação, e irá também introduzir o sistema operacional da mediação dialógica (Turchi \& Gherardini, 2014).

Esta ferramenta, sendo coerente com o estado epistémico da própria área de intervenção (conflito ou controvérsia), é oferecida como um instrumento opcional para a gestão e a promoção da saúde do território onde é usada, oferecendo assim possíveis linhas de intervenção, tanto na antecipação de conflitos, como em situações de emergência. A parte final desta contribuição centrar-se-á nas diretrizes de mediação para as políticas sociais.

\section{NOVOS CENÁRIOS, UM CONTEXTO DE INTERVENÇÃO E RESPONSABILIDADE OPERACIONAL}

O ponto de partida do argumento é colocar os recentes fluxos migratórios numa estrutura histórica e cultural e considerar, através do tempo, os movimentos prolongados de um número significativo de indivíduos de um país para outro, como resultado de situações socioculturais de vários tipos. Estes fluxos (também de uma região para outra ou entre diferentes cidades) têm caracterizado sempre a história da nossa espécie.

Para encontrar uma possível definição de fluxo migratório, vamos considerar as recomendações das Nações Unidas relativamente às estatísticas sobre a migração internacional: "a migração internacional é entendida como o processo de transferência de um cidadão de um país de residência habitual para outro país, por um período de pelo menos 12 meses"'.

Os fluxos migratórios sempre existiram na história da humanidade, devido a vários fatores. Apesar de não perfazerem a totalidade dos casos, muitos destes fatores são económicos, forçando os indivíduos a deslocarem-se de onde existe menos trabalho, ou de onde o trabalho é menos remunerado, para locais onde existe maior procura ou a remuneração é maior.

A zona mediterrânica tem sido sempre um território de pessoas em movimento. Tirando proveito da navegação costeira, as civilizações transformaram as suas iniciativas comerciais em assentamentos estáveis, como os Fenícios, ou impuseram as suas próprias formas de civilização e cultura, como os Bizantinos, os Árabes ou os Normandos (Canale Cama, Casanova \& Delli Quadri, 2009). O cenário europeu atual, face aos conflitos na África Mediterrânea, é uma área de deslocações de jovens que fogem da sua região em direção à Europa, através da porta de acesso que é a Itália.

\footnotetext{
' Retirado de www.un.org
} 
Os fluxos migratórios têm caracterizado historicamente a humanidade: o facto dos grupos se moverem devido a estruturas socioculturais muito diferentes, de passagem ou para permanecer num território, faz com que eles interajam com outras pessoas, gerando assim cenários que podem ir desde contextos de paz até contextos de guerra, com todas as variações intermédias. Se o foco da atenção se mantiver no poder gerador de passar e permanecer, a natureza do processo dos fluxos migratórios é evidente. Isto é, enquanto processo, os fluxos migratórios constroem e geram sempre novas e diferentes estruturas socioculturais (pelo que estamos numa dimensão diacrónica e assíncrona).

Isto significa que, em vez de estudos e intervenções sobre as presumíveis (e falaciosas) causas dos fluxos migratórios, deveríamos focar-nos nas possibilidades operacionais de gerir o que é que os fluxos migratórios geram - ou antecipar o quanto podem gerar - tendo em conta tanto a base social da origem como a do acolhimento.

Nós propomos este foco, de forma a executar ações destinadas a ativar uma gestão avançada que pode ter repercussões para o território, tanto em termos económicos, como na saúde da comunidade. $\mathrm{O}$ foco da intervenção deve estar localizado nas modalidades de gestão socioinstitucional e das estruturas interativas que se modificam como resultado dos fluxos migratórios.

A partir deste momento consideraremos os contextos que exigem "novas" propostas operacionais, não relegados ao acaso, mas sim relacionados com um mecanismo cognitivo que permite a monitorização das formas de gestão que estão a ser usadas. Estas propostas devem considerar o que é gerado e construído na altura em que os grupos de pessoas passam por um determinado território (durante períodos mais ou menos longos) ou se estabelecem numa determinada comunidade de forma (mais ou menos) permanente.

Com base nestas considerações, vemos "novos" cenários (os quais, como foi descrito mais acima, não são novos em termos dos processos que os caracterizam) para os quais o instrumento da mediação pode e deve assumir o controlo na responsabilidade operacional, com respeito pela comunidade.

A partir deste momento, para definir o campo de aplicação da mediação nestes contextos, serão usados os conceitos "comunidade de acolhimento" e "comunidade imigrante". Por "comunidade de acolhimento" referimo-nos à comunidade que, habitando o mesmo território, tem definido as regras da convivência social próprias desse território. Por "comunidade imigrante" referimo-nos às pessoas que, inseridas numa comunidade cujas regras de convivência social foram já definidas (pela comunidade de acolhimento), não participaram na definição dessas regras (Turchi, Fumagalli \& Paita, 2010).

Assim sendo, enquanto a comunidade de acolhimento pode, para gerir os aspetos críticos que "naturalmente" surgem numa comunidade, gerar (caso a caso) modalidades que ao longo do tempo se tornam regras tácitas ou explícitas e convenções administrativas do tecido social, isto não acontece com a comunidade imigrante. Neste cenário, o conflito, embora ainda não tenha sido declarado entre as partes, pode ser antecipado, como se o conflito estivesse numa fase embrionária, num estado de inércia e a seguir se manifestasse subitamente. 
Por outras palavras, o aspeto crítico aqui é que as pessoas constroem a realidade de formas diferentes, pelo que são criadas diferentes estruturas históricas e culturais, as quais, por senso comum, envolvem conteúdos essenciais como as tradições, o vestuário e as diferenças culturais. Pode acontecer que, quando estes sistemas culturais interagem, as diferenças se agravem e se acentuem em maior medida quando o processo de construção não é partilhado. Assim, a dicotomia "comunidade de acolhimento" e "comunidade imigrante" é útil para distinguir as duas partes, mas não é adequada, uma vez que estas partilham o mesmo território, pelo qual são ambas responsáveis.

Em vez disso, o que acontece - como no exemplo apresentado - é que as políticas de gestão da imigração entram em ação assim que concebem os fluxos migratórios como um problema, com perigos contra os quais é preciso proteger e não para gerir a comunidade. Como resultado, são adotadas medidas punitivas ou repressivas para controlar o problema, o que dá origem ao fundamentalismo deste problema e à força destruidora dos seus efeitos. Assim, estas políticas de gestão criam uma contradição: por um lado, as comunidades de acolhimento são descritas como atacadas, ameaçadas, invadidas de mil maneiras e, por outro, os "invasores" são descritos como estando a fugir da miséria e da fome, pessoas transferidas para condições de vida completamente diferentes e, agora, também ameaçadas com agressões físicas.

Além disso, numa comunidade existem diferentes exigências com base na cultura à qual cada um pertence. Em Itália, por exemplo, durante as últimas décadas os fluxos migratórios construíram comunidades de imigrantes que implicam a coexistência de regras e convenções sociais muito diferentes. Em muitos casos isto tem sido gerido pelo senso comum, de acordo com um "princípio laboral": os imigrantes, considerados pela população anfitriã como "aqueles que contribuem de forma significativa para a economia", têm tido respeito e consideração, principalmente devido ao mérito ligado ao emprego (Turchi, Fumagalli \& Paita, 2010).

Relativamente aos exemplos anteriores, é claro que os fluxos migratórios geram situações nas quais a mediação pode ser usada como um instrumento opcional. Assim sendo, as figuras profissionais devem ser competentes na análise dos processos, na antecipação das estruturas da comunidade, na aproximação a soluções que reúnam os requisitos tanto da comunidade de acolhimento, como da comunidade imigrante, ou seja, da comunidade como um todo.

\section{O ESTADO DA ARTE NA MEDIAÇÃO: POSSIBILIDADES OPERACIONAIS E NORMATIVAS}

Após as mudanças sociais geradas pelos fluxos migratórios nos últimos anos, os países da União Europeia têm prestado uma atenção especial à coesão social. De facto, as diferenças entre os vários grupos têm sido radicalizadas ou assumidas como um único ponto de referência para definir e identificar um grupo específico. Isto tem provocado a necessidade (para ambas as comunidades, de acolhimento e imigrante) de criar uma comunidade muito unida. 
Durante a "II Cimeira do Conselho Europeu" em Estrasburgo (realizada em outubro de $1997^{2}$ ), os Chefes de Estado e de Governo Europeus identificaram a coesão social como a estratégia para enfrentar possíveis conflitos entre cidadãos dentro da mesma comunidade. Com este objetivo, o Conselho Europeu ofereceu legitimidade institucional, em termos de um mandato, para propor e implementar intervenções que promovam a coesão social. Especificamente, a coesão social foi definida como "a capacidade de uma sociedade de garantir o bem-estar de todos os seus membros, minimizando as disparidades e evitando a polarização" e uma sociedade coesa é definida como uma "comunidade reciprocamente solidária de indivíduos livres que perseguem estes objetivos comuns através de instrumentos democráticos". Além disso, em 2001, o Conselho Europeu criou o Comité Europeu para a Coesão Social. Esta estratégia comprometeu os 46 Estados aderentes com um programa de trabalhos que descreve a coesão social da seguinte forma:

é um conceito que inclui valores e princípios que definem a condição para garantir que todos os cidadãos, sem qualquer tipo de discriminação, e partindo de uma posição de igualdade, têm acesso aos direitos económicos e sociais fundamentais. A coesão social é um conceito regulamentar que nos lembra constantemente a necessidade de estar atentos à comunidade e cientes de qualquer tipo de discriminação, desigualdade e exclusão. ${ }^{3}$

A 31 de março de 2004, o Conselho de Ministros aprovou a versão atualizada da Estratégia do Conselho Europeu para a coesão social, apresentando a definição e identificando as linhas futuras: a coesão social

é a capacidade de uma sociedade de garantir o bem-estar (prosperidade) de todos os seus membros, reduzindo as diferenças e evitando a polarização. Uma sociedade baseada na coesão é uma comunidade de mútuo apoio de indivíduos livres que perseguem objetivos comuns com significados democráticos. ${ }^{4}$

A regulamentação europeia coloca a coesão social na base das políticas sociais dos países europeus e representa o "modelo social europeu". O mandato operacional de especialistas na mediação também tem como base esta definição de coesão social. Consequentemente, o mediador é um especialista que, ao dispor da comunidade, trabalha para criar comunidades "reciprocamente solidárias e com indivíduos livres que perseguem estes objetivos comuns através de instrumentos democráticos". Com o conhecimento de que caso a comunidade não caminhe na direção da coesão, o resultado será o conflito, o mediador foca-se no "bem-estar de todos os seus membros, minimizando as disparidades e evitando a polarização"s.

\footnotetext{
${ }^{2}$ Disponível em http://www.coe.int/DefaultIT.asp

${ }^{3}$ Retirado de http://www.coe.int/DefaultIT.asp

4 Retirado de http://www.coe.int/DefaultIT.asp

${ }^{5}$ Retirado de http://www.coe.int/DefaultIT.asp
} 
O que foi descrito até este momento mostra que a mediação pode estar fortemente ligada a questões relevantes que envolvem a totalidade da comunidade, a gestão das interações na comunidade e, em termos mais gerais, a saúde e o bem-estar dos seus membros.

\section{Para uma base científica da mediação: a Teoria Geral da Mediação}

Historicamente, as propostas operacionais e teóricas para a intervenção em conflitos têm considerado o objeto de intervenção de formas diferentes, de acordo com a abordagem teórica. Por exemplo, o conflito tem sido considerado como o efeito de "disfunções" comunicativas ou de características próprias das várias partes. Como consequência, o mediador pressupõe a presença de causas específicas do conflito em si. Todas as propostas operacionais e teóricas anteriores de intervenção consideram o conflito como uma entidade factual e empírica, com um estatuto ontológico.

De acordo com o modelo médico, por exemplo, a pneumonia é uma doença dos pulmões e do sistema respiratório, em concordância com o seu estado epistémico e os seus dados factuais e empíricos. Assim, parece coerente e eficaz adotar um paradigma mecanicista para restabelecer a situação à sua condição antes da intervenção da causa. A reflexão epistemológica (Turchi \& Gherardini, 2014) tem revelado tanto erros epistémicos como metodológicos no estudo da mediação. Podemos dizer que procurar as relações causa-efeito é adequado quando podemos identificar as entidades empírico-factuais (como no caso do modelo médico). Contudo, o conflito não pode ser referido como um objeto factual, mas sim como um motus (um processo) com base na linguagem corrente usada pela comunidade de falantes. O seu estado epistemológico é a produção discursiva, com o seu poder gerador e configurativo (aqui referimo-nos ao "processo dialógico"). O conflito, entendido como um elemento processual (dialógico) e não-empírico, deriva do uso de determinadas modalidades de interação e está "por princípio" sempre em mudança.

Quando se usam outros processos discursivos, a forma de interagir altera-se e, como resultado, a configuração da realidade é modificada, com consequências pragmáticas; a configuração da realidade é o que as partes definem como real. A partir daqui, podemos dizer que um conflito sempre pode ser gerido através de intervenções capazes de modificar o processo. Ao adotar este princípio, a intervenção não olha para as causas do conflito, mas sim para a forma como as partes envolvidas constroem a situação de conflito. Este princípio, de acordo com o projeto de pesquisa realizado pela equipa da Universidade de Pádua, e coordenada por Gian Piero Turchi, lança as bases da Teoria Geral da Mediação (Turchi, Tocci \& Romanelli, 2014), a qual oferece a seguinte análise:

1. a legislação é a ferramenta mais utilizada para gerir as interações de conflito (e representa a modalidade básica da Sociedade). Esta ferramenta representa o conjunto de regras escritas compiladas em Códigos (as leis são regras codificadas). A forma de gerir as interações entre as partes, de acordo com a aplicação da Lei, é impor sanções quando a regra codificada (a lei) é violada; 
2. $\quad$ outra forma de gerir as interações de conflito é a mediação, a qual representa a modalidade básica da comunidade. Esta ferramenta é um conjunto de regras de linguagem necessárias para promover a construção de uma regra única e comum às partes.

No contexto dos fluxos migratórios, o papel do mediador é promover as interações entre a comunidade de acolhimento e a comunidade imigrante, para ajudá-las a construir uma mesma realidade. Contudo, num conflito as partes trazem as suas próprias regras e realidades, as quais consideram como definitivas e imediatamente reconhecíveis para a outra parte.

A mediação é assim um instrumento que pode ser usado para intervir em processos interativos - que são processos dialógicos - de delegação, usados pela comunidade relativamente ao sistema de instituições e serviços. E ainda, a mediação pode partilhar as responsabilidades dentro da cidadania para gerir a própria comunidade e, por último, pode antecipar um conflito antes de este ter sido declarado. Isto permite-nos intervir nos processos de delegação relacionados com problemas que pertencem à comunidade, que é quando a responsabilidade para encontrar soluções é atribuída exclusivamente às administrações e serviços. Nestes casos, os resultados podem ser frequentemente insatisfatórios para a cidadania, uma vez que as soluções nestes casos são "impostas" e geradas a partir do "exterior".

\section{Mediação dialógicA}

A tradição operacional da mediação dialógica tem como alvo mudar as configurações discursivas do conflito. A intervenção procura transformar as realidades exclusivas das partes envolvidas numa terceira, e partilhada, realidade, em vez de tentar demonstrar ou determinar alguma coisa (Turchi et al., 2010). Consequentemente, o instrumento opcional da mediação consegue colocar a questão que permite gerar "outras" realidades discursivas e afastar-se da realidade discursiva chamada "conflito". O mediador dialógico cria e usa estratégias retórico-argumentativas que lhe permitem gerar uma configuração da realidade diferente da existente nas produções discursivas das partes do conflito.

Adicionalmente, como a operação da mediação dialógica permite antecipar que um conflito pode ocorrer, o mediador pode usar estratégias para conduzir as partes a partilhar uma realidade única, que não pertence exclusivamente a nenhuma delas. Como habitantes do mesmo território, as partes terão assim a mesma responsabilidade.

O que emerge na comunidade (emergência) é já gerido antes de acontecer. Desta forma, a antecipação de estruturas sociais que promovam a inclusão social, por exemplo, resulta em intervenções que visam promover a cidadania como instrumento de conciliação. Este projeto procura oferecer ao cidadão um papel central e permite lidar precisamente com os aspetos críticos que podem levar à fragmentação das comunidades. 


\section{A MEDIAÇÃO NA CONFIGURAÇÃo DA COMUNIDADE DE ACORDO COM O MODELO DIALÓGICO: $O$ PROJETO do VALE DE CHIAMPO}

O projeto de mediação na comunidade "Do conflito à mediação da vizinhança. $A$ mediação como recurso para a inclusão e o acesso à habitação" no território do vale de Chiampo (de setembro de 2008 a dezembro de 2010) foi uma experiência piloto. Este projeto foi proposto como experimentação, para que os seus resultados pudessem ser transferidos para outros contextos, territórios e países caracterizados pelos mesmos requisitos.

O vale de Chiampo é um território que, devido à forte presença da indústria de curtumes, tem sido caracterizado nos anos recentes por uma afluência significativa de imigrantes (quase $40 \%$ da população). O projeto de mediação na comunidade foi implementado para fazer face a vários acontecimentos críticos provocados pela crise no sector produtivo: o aumento do desemprego entre os imigrantes, o aumento dos pedidos de apoio financeiro das famílias italianas e estrangeiras, a gestão de turmas formadas por estudantes com várias nacionalidades e línguas (Turchi et al., 2010). Antes do projeto de mediação, a estrutura da comunidade tinha sido garantida por aquilo que chamamos, no primeiro parágrafo, a "lógica do trabalho" (que é a visão do imigrante como força de trabalho). Contudo, quando surgiram os acontecimentos críticos mencionados mais acima, os administradores locais e os especialistas da Universidade de Pádua anteciparam que iria haver conflitos caso não fosse promovida a coesão social. Além disso, o conflito teria sido mais sério, devido às interações de muitas e diferentes necessidades e exigências. Todavia, o projeto foi implementado antes da manifestação dos conflitos.

O objetivo da mediação na comunidade é "promover a cidadania como uma responsabilidade partilhada", para que cada indivíduo ocupe o seu lugar na comunidade e contribua para o seu desenvolvimento. A adoção do modelo dialógico permite aos mediadores trabalhar a um nível processual, indo para além dos problemas meramente legais da cidadania.

Uma das estratégicas seguidas para atingir o objetivo do projeto foi a constituição de uma equipa de mediadores no território, com um centro operacional a funcionar 24 horas e sete dias por semana, para reunir os sinais dos cidadãos e desenvolver uma função de vigilância do território. Para construir uma realidade única dentro da comunidade, no início do projeto a equipa da Universidade de Pádua formou cidadãos para serem mediadores não-profissionais e envolveu-os em intervenções com mediadores profissionais. Esta estratégia permitiu a promoção da responsabilidade da cidadania também após o fim do projeto. Outra estratégia que promoveu a responsabilidade para a comunidade foi a constituição de uma sala de controlo, um grupo com a função de procurar aspetos críticos a gerir e escolher as estratégias a seguir.

Os resultados mostraram que as produções discursivas recolhidas no início do projeto foram diferentes das encontradas no final. No início, as populações não contemplavam a existência da possibilidade de gerir a vida da comunidade e delegavam as soluções nas instituições. No final, elas criaram uma estrutura de responsabilidade na comunidade. Além do mais, os resultados mostraram que a coesão social aumentou a 
perceção da segurança. Por último, o projeto ofereceu uma avaliação da eficácia da intervenção concluída e apresentou uma análise custo-benefício para avaliar o impacto do próprio projeto na comunidade, tanto em termos de benefícios obtidos como dos custos que seriam suportados caso tivessem emergido situações de conflito. A análise custo-benefício tornou evidente que a intervenção foi capaz de intercetar situações de conflito e, ao ter antecipado o conflito, o projeto de mediação permitiu uma grande poupança económica dos custos sociais que teriam ocorrido.

\section{Do CONFLITO À SAÚDE DA COMUNIDADE: CAMINHOS PARA A PROMOÇÃo DA SAÚDE DA COMUNIDADE ATRAVÉS DA MEDIAÇÃo}

Depois da descrição geral de um modelo que permite gerir os fluxos migratórios, podemos considerar a definição de coesão social da União Europeia para realizar programas de intervenção. A definição foca-se na "capacidade de uma sociedade de garantir o bem-estar de todos os seus membros"6. Embora esta definição nos permita intervir a vários níveis, a construção do bem-estar é um conceito que permanece indefinido.

É necessário definir o que consideramos como "bem-estar", caso contrário, assumindo que o significado é conhecido, não conseguimos observar as suas repercussões pragmáticas e, como consequência, a intervenção pode tornar-se inválida. Por esta razão, no modelo dialógico "bem-estar" é substituído por saúde. A saúde é definida como: o conjunto de produções discursivas que promovem uma gestão daquilo que é gerado no seio da comunidade, através do uso de processos de antecipação e prefiguração de cenários futuros que, ainda que não disponíveis, são possíveis. A promoção desta estrutura é exatamente aquilo que a mediação deve ser capaz de fazer.

Dizer que a mediação é um instrumento para promover a saúde da comunidade, significa que esta pode ser usada antes que o conflito mostre os seus efeitos pragmáticos e, ao mesmo tempo, que este instrumento funciona de forma que a comunidade, vista como responsável pela sua própria saúde, pode realizar processos que conduzam a um aumento da coesão social. Assim, a mediação trabalha com objetivos relacionados com a promoção da saúde da comunidade. A mediação, em conjunto com outros serviços sociais, permite promover a saúde da comunidade ao definir e delimitar instrumentos específicos, de forma a que não haja uma sobreposição com as intervenções que outros serviços possam realizar, mas sim um trabalho em rede. A promoção da saúde da comunidade é um valor acrescido que a mediação pode criar e gerir eficazmente com vista a desenvolver sinergias entre os serviços e a atingir um objetivo que simplifique todos os serviços e cuja meta é a promoção da saúde da comunidade. Depois do caminho argumentativo deste artigo, esta última parte é dedicada aos caminhos operacionais abertos que promovem a mediação como um instrumento para promover a saúde. E estes são:

- a adoção de uma referência epistémica adequada ao objeto da intervenção, que é, o conflito ou a controvérsia;

\footnotetext{
${ }^{6}$ Informação retirada do Plano de ação do Conselho Europeu para a coesão social, "Nova estratégia e Plano de ação do Conselho Europeu para a coesão social", aprovado pelo Conselho de Ministros do Conselho Europeu, a 7 de julho de 2010.
} 
- a referência explícita aos fatores operacionais que visam garantir a eficácia das intervenções, para além da eficiência do serviço de mediação;

- $\quad$ a formação de especialistas profissionais em processos de mediação. Estes profissionais, disponíveis para as comunidades, atuam como células sensoriais do território, antecipando conflitos e prefigurando possíveis cenários futuros;

- a referência aos objetivos gerais do serviço de mediação, que considera a saúde do território, a segurança e a coesão social como produtos do diálogo entre todos os protagonistas;

- $\quad$ a adoção de formas de intervenção que incluam a avaliação da sua eficácia e a análise da pertinência das intervenções para o seu contexto social. /

Tradução: Núria Santos

\section{REFERÊNCIAS}

Canale Cama F., Casanova D. \& Delli Quadri R. M. (2009). Storia del Mediterraneo moderno e contemporaneo. Napoli: Guida Editori.

Turchi, G. P., Fumagalli, R. \& Paita, M. (2010). La promozione della cittadinanza come responsabilità condivisa. L'esperienza pilota di mediazione civica sul territorio della Valle del Chiampo. Padova: Upsel Domeneghini.

Turchi G. P. \& Gherardini V. (2014). La mediazione dialogica. Fondazione scientifica, metodo e prassi in ambito penale, civile e commerciale, familiare e di comunità. Milan: Franco Angeli.

Turchi, G. P., Tocci, M. \& Romanelli M. (2014). Libro bianco per la promozione dell >>efficienza nell'Ammistrazione della Guistizia - proposte in materia di risoluzione stragiudiziale dei conflitti e delle controversie. Padova: Cleup.

\section{NOTAS BIOGRÁFICAS}

Gian Piero Turchi é professor de Psicologia Clínica e Psicologia das Diferenças Culturais na Universidade de Pádua e diretor do curso de pós-graduação "A mediação como método operacional em contextos familiares, criminais, da comunidade, civis e comerciais". É também Presidente do Fórum Mundial de Mediação e autor de várias publicações, tais como: "Valutare e misurare l'impatto biografico di un evento dannoso: lo strumento M.I.B" (2018); Minori e giustizia. La mediazione come strumento efficace ed efficiente per un ruolo attivo del minore nella comunità (2016); Libro bianco per la promozione dell"efficienza nell'Ammistrazione della Guistizia - proposte in materia di risoluzione stragiudiziale dei conflitti e delle controversie (2014) e Flussi migratori, comunità e coesione sociale. Nuove sfide per la mediazione (2013). Colabora, como consultor, com a Direção para métodos alternativos de resolução de conflitos (D.I.M.A.R.C) do Ministério da Justiça de Córdoba, Argentina.

ORCID: 0000000221545339

Email: gianpiero.turchi@unipd.it, gianpiero.turchi@gmail.com

Morada: Dipartimento di Psicologia dello Sviluppo e della Socializzazione - DPSS, Universidade de Padova, Via Venezia 8, 35131 Padova 
Michele Romanelli é psicólogo, mediador e professor do curso de pós-graduação "A mediação como método operacional em contextos familiares, criminais, da comunidade, civis e comerciais". É ainda autor de publicações como: "Valutare e misurare l'impatto biografico di un evento dannoso: lo strumento M.I.B" (2018); Libro bianco per la promozione dell'efficienza nell'Ammistrazione della Guistizia - Proposte in materia di risoluzione stragiudiziale dei conflitti e delle controversie (2014); Flussi migratori, comunità e coesione sociale. Nuove sfide per la mediazione (2013).

ORCID: 0000-0002-5634-1117

Email: info@micheleromanelli.it

Morada: Dipartimento di Psicologia dello Sviluppo e della Socializzazione - DPSS

Universidade de Padova, Via Venezia 8, 35131 Padova

* Submetido: $20 / 07 / 2018$

* Aceite: $30 / 10 / 2018$ 